\title{
Responding to schoolgirl pregnancy: the recognition and non-recognition of difference
}

\author{
Kerry Vincent \\ University of Nottingham, UK
}

\begin{abstract}
Teenage mothers in the UK have been found to be at risk of early school leaving, low levels of educational achievement and low levels of post-compulsory educational participation. Current policy in the UK emphasizes the importance of education as a way of improving the life chances of those who become pregnant while young and, as part of that, schools are encouraged to support the educational inclusion of those who become pregnant while still of statutory school age. Drawing on repeat qualitative interviews conducted over a 15-month period, this article examines the educational experiences of a group of students in one local authority in England who became pregnant while still at school. Particular attention is paid to how different schools addressed the 'dilemma of difference' posed by teenage pregnancy and how school attitudes and practices enhanced or inhibited educational participation.
\end{abstract}

Keywords: dilemma of difference, inclusion, recognition of difference, teenage pregnancy

\section{Introduction}

\section{The research context: pupils at risk}

A consistent finding in research on teenage pregnancy and education is the strong and enduring correlation with low educational participation rates and poor educational outcomes. As noted by the Audit Commission a decade ago:

One group that can easily lose out in their education is pregnant schoolgirls and schoolgirl mothers. In LEAs that could provide figures, there are usually more girls in this category than there are girls who are permanently excluded. (Audit Commission, 1999: 61)

Other research at the time confirmed that teenage mothers were at risk of early school leaving, low levels of educational achievement and low levels of post-compulsory educational participation (Coleman and Dennison, 1998; Kiernan, 1995). More than one third of the mothers who participated in the Teenage Pregnancy Strategy Evaluation (TPU, 2005) were found to have left school before the statutory school leaving age and to experience difficulties in returning to education. 
Researchers also agree about the nature of the challenges that pregnant and mothering teenagers face in continuing their education. Local authorities, for example, have been found to place a low priority on getting pregnant and mothering students back into education (Coleman and Dennison, 1999) and instances of girls being pushed out of school for health and safety reasons have been found to be common (SEU, 1999). There is also evidence of some pupils being excluded from school, or strongly 'encouraged' not to attend because of pregnancy while others stop attending because of bullying (DCSF, 2007b; Osler and Vincent, 2003). This, for many, marks the beginning of a more permanent detachment from education (Dawson, 1997; SEU, 1999).

\section{The policy context: education and the teenage pregnancy strategy}

The launch of the UK's national teenage pregnancy strategy in 1999 marked the beginning of a focused 10-year campaign to reduce conception rates and increase participation of teenage parents in education, training or employment. This strategy sits alongside the government's wider efforts to tackle social exclusion and aims to address the negative health, economic and social correlates of teenage pregnancy. As part of this strategy the government set a national target to increase the number of young parents engaged in learning or employment to 60 per cent by the year 2010 .

In 2001, in support of the national teenage pregnancy strategy, the Department for Education and Skills (DfES) issued guidance on the education of school-aged parents which outlined expectations on schools and local authorities (DfES, 2001). For schools, the guidance stated that pregnancy is not a reason for exclusion and that health and safety reasons should not be used to prevent a pupil from attending. This point is reiterated in other key documents, such as those relevant to managing attendance and exclusions (DCSF, 2007a; DfES, 2003, 2005). As stated in point 14.4 of the 2001 guidance: 'The school should ensure that the young woman continues learning as long as possible up until the birth by exploring all opportunities for curriculum support available' (DfES, 2001: 5).

Four years later, as documented in the mid-term evaluation of the teenage pregnancy strategy, the educational lot of the pregnant schoolgirl seemed not to have improved (TPU, 2005). This research found that:

Participation rates of young mothers changed little during the evaluation period. Many pregnant schoolgirls continue to find it difficult to complete their education in school, and young mothers continue to face problems in balancing the demands of childminding and work or studying. (TPU, 2005: ii)

As the end of the 10-year strategy approaches, a further look at what is happening in schools in relation to pregnant schoolgirls seems timely. By drawing on the experiences of young women who became pregnant while still at school, this article aims to provide insights into how schools promote or work against educational participation through the way that pupil differences are recognized and responded to. It focuses in particular on how different schools addressed the 'dilemma of difference' posed by a pupil pregnancy and how resulting attitudes and practices enabled or hindered educational participation.

I begin by highlighting some connections between the work of scholars Martha Minow and Nancy Fraser. While their academic and research foci differ, both bring to their work a strong interest in social justice as it relates to 'difference'. Their respective views on 
difference are used as a framework through which to examine the experiences of the participants in this study. Using Fraser's concept of a differentiated recognition of difference, I argue that it is only by ignoring some differences while simultaneously attending to others that educational participation for pregnant and mothering schoolgirls can sensibly and fairly be supported. This argument may be equally applicable to other groups of students who are identified as vulnerable or who find themselves on the educational margins.

\section{Theorizing difference}

In her book Making All the Difference (1990), American legal scholar Martha Minow examines the legal and political responses to difference. Her educational interests have focused on bi-lingual and special education but she makes a number of points that are equally relevant to the discrimination experienced by any pupil who is identified as different. First, alongside others with an interest in social justice, she notes that when individuals or groups are marked out as different, such difference nearly always carries a stigma a socially constructed stigma based on the perceptions and unquestioned assumptions of the dominant culture (see Corbett, 2001; Fraser, 1997; Young, 1990 for similar views).

Second, she illustrates that policy responses to discrimination generally take one of two forms - specifying either equal treatment or special treatment. Minow argues that ignoring difference through a 'treat everybody the same' approach and attending to difference through a 'special treatment' approach can both have negative consequences for the individuals concerned. She explains that an 'equal treatment' approach inevitably requires ignoring the circumstances that may have contributed to the inequality in the first place while the 'special treatment' approach means highlighting the ways in which an individual or group is different from the norm thus unnecessarily reinforcing notions of difference that may further stigmatize.

She illustrates with the example of pupils in American schools whose first language is not English. She asks if justice is best served through treating these pupils the same and teaching in English, thus ignoring the impact this will have on their immediate education, or through teaching them in their first language, thus placing them at risk of disadvantage in the future? The issue she highlights is that special treatment can both address and accentuate the stigma of difference. She refers to this as the 'dilemma of difference' which she expresses through the questions:

When does treating people differently emphasize their differences and stigmatize or hinder them on that basis? And when does treating people the same become insensitive to their difference and likely to stigmatize or hinder them on that basis? (Minow, 1990: 20)

Minow's 'dilemma of difference' resonates with the social justice work of political scientist Nancy Fraser. Fraser (1997) is critical of approaches to social justice that focus primarily on cultural recognition while marginalizing issues of distribution. ${ }^{1}$ That is, she is critical of a politics of difference that does not also recognize the political and the economic.

Fraser argues that achieving social justice requires both redistribution of material resources and cultural recognition of difference - that is to say, both equal treatment and different treatment. However, as these two remedies do not sit neatly alongside each other there is a challenge in pursuing both simultaneously. Reflecting Minow's dilemma of difference, the question Fraser poses is: under what conditions can a politics of recognition support a politics of redistribution and when does it undermine it? 
Her proposed solution is a differentiated recognition of difference - that is, recognition of different kinds of differences, some to be eliminated (non-recognition), some to be universalized (recognition), and some simply to be enjoyed. She argues that it is in this way that a politics of redistribution can be reconciled with a politics of recognition. In a similar way, I propose that Fraser's view that not all differences should or need to be attended to, goes some way towards addressing Minow's dilemma of difference.

The following section provides details about a small-scale qualitative study undertaken in one local authority in England. The experiences of five of the participants in this study are then used to illustrate Minow's dilemma of difference and to examine how the various responses of the five schools concerned relate to Fraser's concept of a differentiated recognition of difference.

\section{Research in one local authority}

The data on which this article is based are drawn from a larger doctoral study on the educational experiences of pregnant schoolgirls and schoolgirl mothers. The study aimed to deepen understandings about girls' educational experiences and the factors that helped or hindered educational engagement and outcomes. A key aspect of the research involved an evaluation of the relative strengths and limitations of current policy and practice relating to education.

As participants' experiences and their perceptions of those experiences were central to the study, a qualitative interview approach was adopted (Holstein and Gubrium, 1995; Rapley, 2004). In-depth, semi-structured repeat interviews (McDowell, 2001; Reinharz, 1992) were undertaken with 14 young women in one local authority in the English Midlands between March 2007 and May 2008. They had attended nine different secondary schools. Within this local authority, teenage pregnancy rates were high and supporting young mothers was a priority. Over the course of the study, nine participants were interviewed three times, six were interviewed twice and two were interviewed once. Initial interviews took place at the participant's educational institution while most of the subsequent interviews took place in participants' homes. Interviews lasted between 35 and 55 minutes in duration and were audio-recorded and later transcribed.

Participants were accessed, with the support of the local authority teenage pregnancy co-ordinator and the reintegration officer, through a range of educational institutions and services (one school, three educational alternatives and the Connexions service ${ }^{2}$ ). The local authority concerned provided a pupil referral unit (PRU) for pregnant and mothering schoolgirls which could accommodate a limited number of pupils. While this centre performed an important function in terms of supporting educational continuity, it is not the focus of this article.

Young women were invited to participate via an initial meeting arranged at the educational institution - or in two cases, through the Connexions service. The purpose of the research was explained and issues of informed consent, right of withdrawal and anonymity were discussed (Morrow and Richards, 1996; Williamson et al., 2005). Information sheets and consent forms were left and subsequently collected. Where participants were 16 years or younger, written parental consent was also obtained.

At the time of the first interview participants ranged in age from 15 to 18 years, with the majority (11) aged 16 or 17 years. Nine were already parents while the remaining five 
were pregnant. Twelve of the 14 participants were still of statutory school age when they first became pregnant. A narrative analysis (Elliott, 2005; Hollway and Jefferson, 2000) focused on identifying the sorts of school actions that helped a participant to remain engaged in education and those that hindered. Attention was given to both process and outcome and also how participants perceived and reacted to their varying circumstances.

\section{The recognition and non-recognition of difference}

Across the larger study, school responses to revelation of a pupil pregnancy varied considerably and ranged from informal exclusion, to reluctant acceptance, to supportive acceptance. Despite current policy, staying in mainstream was the exception rather than the norm. In addition, some participants had very little, and in some cases no input into the processes to which they were subject once they became pregnant.

Of the 12 participants who were still of statutory school age when they became pregnant, four were directed immediately to the PRU, even those who were early in their pregnancy. Two participants had already ceased attending their schools prior to pregnancy and alternative educational arrangements, albeit limited, were eventually made. Three pupils were effectively excluded from their schools with no satisfactory alternative arrangements being made while the remaining three were supported to continue in their mainstream schools, at least for a period of time.

This article draws on the experiences of the latter - Shae, Mia and Rebecca. By way of contrast, I also introduce Sonia, one of the pupils who was effectively excluded from school because of her pregnancy, and also Libby who returned to her old school as a teenage mother after spending time at the PRU. It is through the experiences of these five students that I examine the ways in which the difference of teenage pregnancy was recognized, what forms this recognition took, and what impact this had on these particular pupils. All names used in this article are fictitious.

\section{School responses to pupil pregnancy}

Shae had a somewhat tumultuous journey through Years 8 and 9 but, like many of the other participants, reported taking her education more seriously as she moved into Year 10. As was also true of most of the other participants, her pregnancy came as a considerable shock and being only part-way through Year 10, she was anxious about the impact on her education. Resulting primarily from the attitudes and actions of one particular teacher, arrangements were made for Shae to continue her education in her school. Speaking of this teacher Shae reported:

It was Miss $[\mathrm{x}]$. She was the one that mostly arranged everything . . . cause all my work . . I was just going to finish ... and they were all wanting me to pass ... they were saying, 'oh, you're doing so good and now we're going to have to lose you' and stuff like that ... so she was the one that was asking all the other teachers if I could stay and carry on with my work.

Several points in this excerpt are noteworthy. First, it was evident that most staff members assumed that Shae's pregnancy meant she would have to leave the school - expressed through the sentiment 'now we're going to have to lose you'. Second, this was presented as a shame now that she was 'doing so good' compared to previous years. Miss [X] however, had a different view and under her persuasive influence other staff members came to question their initial assumption. Shae's ongoing attendance was subsequently supported by all her teachers. 
The first important step in supporting Shae's educational continuity had been achieved. Her pregnancy was not perceived as a difference that counted or that required her to be viewed differently from other pupils in terms of school attendance. Through this nonrecognition of difference she was encouraged to stay in school despite her pregnancy. The implicit messages conveyed by this non-stigmatizing acceptance of her pregnancy were: 'Your pregnancy is irrelevant, you are a valued member of our school and belong here.'

This contrasts markedly with the experiences of Sonia whose story was one of rejection because of her pregnancy. Her account provides an example of non-helpful recognition of difference. When the school was informed of her pregnancy, even though she was in the early stages and there were no visible indicators, she was made to feel acutely aware of her difference. This was mediated through sideways glances 'like there was something wrong with me' and through ignoring her academic needs. The former resulted in feelings of shame and self-consciousness while that latter resulted in loss of motivation for her own academic progress. Speaking of her school's response to her pregnancy, Sonia said: 'It was horrible, because when I fell pregnant they just dropped me and just left me.' On inquiring what she would like the school to have done to be more supportive she replied:

Meet with me. They never even sat down and had a meeting with me. And like all the teachers just used to like look at me sideways like there was something wrong with me ... and they just left me to do whatever I was doing. If I didn't do my work or if I didn't know how to do it, they just ignored me. I was like, well if they can't be bothered with me, I can't be bothered to be here.

When Sonia stopped attending school, prompted by both morning sickness and feelings of rejection, there was initially no follow up and health and safety reasons were subsequently used to justify her ongoing exclusion. She explained that:

They wouldn't let me in because of insurance. I wanted to go back but they just said we don't have insurance to cover pregnancy.

Sonia's school eventually arranged for her to receive four hours home tuition per week but as the school failed to provide relevant work to the home tutor, Sonia continued to feel abandoned. The indirect but clear message conveyed by the school was that pregnancy and school were mutually exclusive. The ultimate outcome for Sonia was a complete disengagement from education.

These two examples can be viewed using Fraser's concept of a differentiated recognition of difference. In Sonia's case, the difference of teenage pregnancy was recognized as one that could not be accommodated with the school. Implicit within the responses of her school were the messages: 'you don't belong here anymore' and 'your education is no longer important to us'. Shae's school, on the other hand, viewed her pregnancy in nonstigmatizing ways and simply as one more difference to be accommodated within the school. By not attending to the difference of pregnancy per se, Shae's school conveyed that she was still a valued member of the school whose ongoing attendance was both expected and wanted. The subsequent recognition of specific pregnancy-related differences were mediated through a range of relatively minor practical accommodations. These included flexibility with uniform requirements, movement around the school, seating arrangements and access to toilet facilities. For example, she was given a late pass that allowed her to arrive in class a few minutes after her classmates so that she could avoid crowded corridors as she moved around the school, and also a toilet pass in recognition of her need to use the toilet more frequently. 
While the two scenarios outlined above minimize other factors that may have been influential, such as pupil history within the school, they are still useful illustrations of the way in which a school response to difference can result in two very different pupil outcomes. In the following section, the experiences of two additional participants are described to illustrate Minow's dilemma of difference.

\section{Pregnant schoolgirls: the same but different}

Mia, like Shae, remained at her school until she was more than seven months pregnant, after which she received home tuition. She experienced mixed reactions from staff, perceiving some to be positive and supportive with regard to her pregnancy and others judgmental and unsupportive. I include parts of her story here in order to explore a theme common to all three pupils who continued in their schools - the desire to be treated both differently and no differently from their non-pregnant classmates.

When Mia sometimes did not complete all her work in the latter stages of her pregnancy, because of tiredness, she thought that teachers were more lenient with her than they were with other pupils. While on one hand she perceived being treated differently as coming from a place of intended support, what she would have liked at that point was more encouragement to complete work rather than simply being able to get away with things. She wanted some leeway but not too much, and leeway around certain things but not others. As she explained:

It upset me really ... cause even though I know it was a bit my own fault getting pregnant ... and l'd stop doing the work sometimes ... but they could have pushed me a bit ... they could have talked to me the way they talked to anyone else. Just because l'm pregnant doesn't mean treat me different.

On the other hand, there were other situations where she thought it important to have some acknowledgement that her circumstances were different. She identified one obvious practical matter to do with physical comfort - namely that the normal school chairs and desks were not comfortable, particularly in the latter stages of pregnancy. However, at a less obvious level, she also suggested that an occasional simple inquiry about how she was doing would have been appreciated. Speaking about both, she suggested:

I think sometimes, something like having a comfy chair is good, but you don't need that until you're say seven months pregnant . . . but it's just things like asking how you are. Like obviously you don't ask everybody that, but if you're coming in heavily pregnant, it would have been nice sometimes to have been asked.

This was a point also noted by Shae and Rebecca. Both spoke about feeling more emotionally volatile throughout their pregnancies and attributed this to fluctuating hormone levels. They recounted that some days they found themselves upset about things that they normally would have brushed to one side. In order not to be perceived as different, Shae kept her sensitivities to herself. This meant absenting herself to the toilet on several occasions so that no-one would see her cry. As she explained:

When you're pregnant it's your hormones [laughing]. Yeah, you take things to heart ... and the teachers, they just see it like you shouldn't be pregnant anyway and any problems and it's like, 'well you shouldn't have got pregnant', things like that. [pause] But I was a hard nut. I wouldn't let anyone know, like if l'd cried ... l'd go off to the toilets. 
Fluctuating hormone levels, tiredness and discomfort are realities for a pregnant pupil, as has been noted in other research (Alldred and David, 2007; Luttrell, 2003). Indeed, in their work on sex and relationship education in schools, Alldred and David (2007) point to this as one factor contributing to school discomfort with accommodating a pregnant pupil. With reference to a pregnant pupil they suggest that 'the image of her bulging body and perhaps tearful outbursts highlight the naturalised absence of emotion and the body from the dominant pupil discourse' (Alldred and David, 2007: 179). For the pupils in this study, wanting to be treated the same despite these issues appeared to be important. Shae explained that the stairs were tiring, the chairs and desks were uncomfortable, and that some afternoons she really would have liked a short rest after dinner - but she also liked not being singled out as different from her peers even though it was sometimes hard. She recounted:

It was the stairs that did me in . . cause my belly was sticking out so far. And l'd have to push my chair back, otherwise I wouldn't fit [at my desk] . . . but they didn't really treat me any different. That's what I liked. But it was hard some days ... like say you'd had dinner and the bell went, you had to go [to class] . . . even if you weren't feeling very good.

Despite these difficulties, it was being treated the same that she valued and that helped convey a sense of belonging. Her view on what schools could do to make it easier for pregnant pupils was:

Well, just treating them all the same really, in'it . . . making them feel like they're [pause] wanted [at school] ... else you're not gonna want to get up and go.

Rebecca also emphasized not wanting to be singled out as different. She did not want to leave class a little earlier or later to avoid crowded corridors, as did Shae. She wanted to move from class to class with her friends. She applied the same thinking to her exams she did not want to be sitting in a room on her own - she wanted to be 'normal'. Speaking of her exams, she reported:

When it came to doing my GCSEs ${ }^{3}$ I was really close to my due date so they said I could go into a separate classroom on my own and do them but I said no. I wanted to be normal so I was in the middle of the hall on my little desk.

Similarly, she rejected the health and safety reasons used by some schools to dispatch pregnant girls. She explained:

I did the steps every day. It's not like, 'you're pregnant, you [therefore] can't walk up and down these stairs'. If the fire alarm went now, we'd have to use the stairs to get out of here, you know what I mean?

Rebecca also took exception to the 'pregnancy as disease' discourse that she perceived (Pillow, 2004). Her school had initially been reluctant for her to continue but she did not see pregnancy as a reason for being 'sectioned' (excluded) and she was aware that the other two options available to her, home tuition or the PRU, provided only limited access to the curriculum to which she was entitled. She wanted all her GCSEs and she knew that staying in school was her best way of achieving them. Similar to the view adopted by staff in Shae's school, Rebecca's view was that being pregnant was irrelevant to her ability to continue working towards her GCSEs alongside her non-pregnant 
classmates. However, it was only after some persuasion that her school adopted this same stance of non-recognition. As she explained:

I said to my teachers and Miss [Head of Year] and everyone that was there [at the meeting], basically, why should I go and do my studying at home just because I'm pregnant. I've not got some disease, l'm just carrying a baby. There's no point in me being sectioned like that. I'm still as capable of doing my GCSEs ... as I [subsequently] proved. And it took me a lot of persuading, cause they weren't happy about it at first, but I did it.

Interestingly, her reference to being viewed as contagious points to the possibility that it is not the difference of pregnancy per se, but rather what it represents that is being silently recognized - namely, that adolescent sexuality has not been contained, which therefore makes her morally contagious. This then is not simply a case of recognition or non-recognition of difference, but rather a case of misrecognition.

\section{A school-aged mother: the same but different}

I turn now to the experiences of Libby. Her situation was different in that she was returning to school after having had her baby, but the issue of wanting to be treated both the same and differently remains a common theme as does the dilemma this poses about what is best and what is just.

On becoming pregnant during Y10 Libby had been directed to the PRU but she returned to her mainstream school the following year when the on-site nursery at the PRU was no longer able to cater for her eight-month-old son. Libby therefore faced the prospect of completing her final year of schooling in a mainstream school she had not attended for over a year, having had limited access to the National Curriculum during her absence, and as the mother of an eight-month-old child. How were these differences to be recognized and responded to?

In our first interview Libby explained that she had initially been reluctant to return to her old school. This was because she was unsure of how staff and peers would react to her return. As was also true of the other participants, and as is highlighted in much of the qualitative research with young mothers (Coleman and Dennison, 1998), she seemed acutely aware that the difference of teenage pregnancy is a very stigmatized one. She explained being particularly nervous on her first day because:

Because of the people here. I thought I wouldn't get along with them again. I thought they might think differently about me with having a baby and that.

By the second interview Libby reported having made new friends and that on the whole she was enjoying school although she found some aspects hard. She attributed her successful reintegration to school primarily to the school's positive attitude towards her return, to non-stigmatizing attitudes from staff and classmates, and to the school's pragmatic and flexible responses to her different circumstances.

As part of her reintegration plan it was agreed that Libby would undertake a part-time programme working towards three National Vocational Qualifications (NVQs). She thought that this was appropriate for her needs and was one way of enabling her to juggle school alongside motherhood. She came to school just for those subjects while a childminder looked after her son. However, even on this part-time arrangement, she 
found the dual demands of parenting and school very tiring. This was particularly true when her son was teething and she was up in the night with him. She consequently sometimes missed days of school due to tiredness and thus risked getting behind with her work. She appreciated what she perceived as considerable commitment from her English teacher who would take the time to go over work she had missed.

Nevertheless, some days Libby still found juggling motherhood and school a challenge. She simultaneously appreciated the fact that the school treated her just like any other pupil by phoning her if she missed more than one consecutive day, yet at the same time felt somewhat pressured. As she explained:

When I was really tired it was hard for me to do all my work and I would be falling asleep in class. They were just always on to me and that was making me worse, and sometimes I used to get depressed from school because I was so tired . . . cause when I started back at school I was up during the night with him [my son] because he was teething.

What can be seen in this example is that Libby's reintegration to school was supported through a combination of recognition and non-recognition of difference. Being offered a part-time timetable was one way of recognizing that although she was legally required to be in education she was also the primary caregiver of a teething child. The implicit message conveyed through this arrangement was 'your education is important but we recognize that you also have other responsibilities'. Similarly, extra help from one of her teachers after an absence was another way of recognizing the demands of motherhood.

At the same time, in other respects, Libby was treated just like any other student and the fact that she was also a mother was treated as irrelevant (non-recognition of difference). A phone call home after more than one day of unexplained absence conveyed the message that 'we expect all our students to attend regularly even if you are a mother as well as a student'. As the excerpt above illustrates, this was not without its tensions and Libby experienced this as both helpful and non-helpful.

Linking to Minow's dilemma of difference, one might well consider the potential future disadvantage to be experienced by Libby as a result of her part-time study and as a result of pursuing NVQs (National Vocational Qualifications) rather than GCSEs. On the other hand, the juggling of just three subjects alongside motherhood seemed to be as much as one could reasonably ask of this pupil, at this time.

\section{Responding to the difference of schoolgirl pregnancy: what can be learned?}

In this article I have presented a focused and inevitably limited analysis of one aspect of the lives of five young women in one local authority in England. For current purposes, the analysis has not dealt with other factors that impacted on these young women's lives, such as those related to gender or class, or the interface between these 'differences' and schooling. Instead, I have concentrated on how schools recognized the difference of teenage pregnancy and what impact such recognition had on these particular individuals. In doing so, I have aimed to illustrate how, in the mainstream school context, Fraser's concept of a differentiated recognition of difference may provide a useful way of responding to Minow's dilemma of difference. 
The study found that, despite current guidance and despite expectations that schools accommodate a wider range of pupil differences than in the past, some schools responded to teenage pregnancy as a difference that could not (or should not) be accommodated within mainstream education. Dubious health and safety grounds, or 'her needs are better met elsewhere' thinking were used to exclude a young person from mainstream education - and possibly, from her best chance of achieving enough GCSEs to ensure future educational options. In these cases, pupil exclusion was justified by highlighting the ways in which a pregnant pupil was different from her non-pregnant peers while ignoring the ways in which she was similar. As exemplified by Sonia, this resulted in feelings of rejection and shame and led to further disengagement from education.

The schools attended by Shae, Mia, Rebecca and Libby, however, adopted a flexible approach to policy implementation. This approach reflects what Fraser would refer to as a differentiated recognition of difference - a pragmatic 'treat them the same' and a 'treat them differently' approach. Flexibility with regard to school uniform, movement around the school, seating arrangements, access to toilet facilities, part-time study and additional support with learning are examples of helpful recognition of difference related to pupil pregnancy or motherhood. At the same time, non-recognition of difference was conveyed through having the same expectations of pregnant pupils with regard to educational continuity, regular school attendance and completion of course work. These various school responses resulted in participants feeling cared about and valued as members of their schools and served to promote educational motivation. Such an approach acknowledges that it is only by ignoring some differences while simultaneously attending to others that educational participation can sensibly and fairly be supported.

As Fraser would argue, addressing the dilemma of difference in ways which are likely to support the educational participation of pregnant and mothering teenagers will require both positive recognition of difference and non-recognition of difference. It will also involve challenging some of the taken-for-granted assumptions that are often made about pregnant and mothering schoolgirls, such as the idea that staying on in school is neither appropriate nor wanted by them. While there may be no perfect solution to resolving Minow's dilemma of difference, as illustrated most clearly in Libby's case, Fraser's concept of a differentiated recognition of difference provides a useful model whereby less stigmatizing and more affirming attitudes and practices towards all pupils, no matter what their differences, might emerge.

The author can be contacted via email at: ttxkav@nottingham.ac.uk

\section{Acknowledgements}

The author wishes to thank the two anonymous reviewers for their invaluable comments in preparing this article for publication and to her supervisor Pat Thomson for her ongoing guidance.

\section{Notes}

1 See Fraser's critique of Iris Marion Young in chapter 8 of Fraser (1997).

2 Connexions is a centrally-funded, locally administered service whose prime remit is to ensure that all 13-19-year-olds receive the support or guidance that they might need to achieve a smooth transition from compulsory to post-compulsory education or employment.

3 General Certificate of Secondary Education - the subject-based nationally recognized academic award undertaken by secondary school students in the UK in their final two years of compulsory education. 


\section{References}

Alldred, P. \& David, M. (2007) Get Real About Sex: The Politics and Practice of Sex Education. Milton Keynes: Open University Press.

Audit Commission (1999) Missing Out: LEA Management of School Attendance and Exclusion. Northampton: Belmont.

Coleman, J. \& Dennison, C. (1998) Teenage parenthood. Research review. Children and Society, 12(4), $306-14$. Corbett, J. (2001) Supporting Inclusive Education: A Connective Pedagogy. London: Routledge.

Dawson, N. (1997) The provision of education and opportunities for future employment for pregnant schoolgirls and school girl mothers in the UK. Children and Society, 11(4), 252-63.

Department for Children Schools and Families (DCSF) (2007a) Guidance on exclusion from school. Online: http://www.teachernet.gov.uk/wholeschool/behaviour/exclusion/guidance2007/ [accessed 5 August 2008].

Department for Children Schools and Families (DCSF) (2007b) Teenage Parents Next Steps: Guidance for Local Authorities and Primary Care Trusts. Improving Outcomes for Teenage Parents and their Children. Nottingham: DCSF.

Department for Education and Skills (DfES) (2001) Guidance on the education of school age parents. Online: www.dfes.gov.uk/schoolageparents [accessed 25 September 2007].

Department for Education and Skills (DfES) (2003) Key Stage 3 National Strategy. Advice on Whole School Behaviour and Attendance Policy. Ref 0628-2003. Annex C: Guidance on Behaviour and Attendance: Attendance Policy. Birth of a Child. Nottingham: DfES.

Department for Education and Skills (DfES) (2005) Advice and guidance to schools and local authorities on managing behaviour and attendance: groups of pupils at particular risk. Online: http://www.dfes.gov.uk/ behaviourandattendance/uploads/Groups\%20at\%20Risk.doc.

Elliott, J. (2005) Using Narrative in Social Research. Qualitative and Quantitative Approaches. London: SAGE. Fraser, N. (1997) Justice Interruptus. Critical Reflections on the 'Postsocialist' Condition. New York: Routledge. Hollway, W. \& Jefferson, T. (2000) Doing Qualitative Research Differently. Free Association, Narrative and the Interview Method. London: SAGE.

Holstein, J. \& Gubrium, J. (1995) The Active Interview. London: Sage.

Kiernan, K. (1995) Transition to parenthood: young mothers, young fathers - associated factors and later life experiences. Welfare State Programme Discussion Paper 113, London School of Economics.

Luttrell, W. (2003) Pregnant Bodies, Fertile Minds. Gender, Race, and the Schooling of Pregnant Teens. London: Routledge.

McDowell, L. (2001) 'It's that Linda again': ethical, practical and political issues involved in longitudinal research with young men. Ethics, Place and Environment, 4(2), 87-100.

Minow, M. (1990) Making All the Difference: Inclusion, Exclusion and American Law. Ithaca, NY: Cornell University Press.

Morrow, V. \& Richards, M. (1996) The ethics of social research with children: an overview. Children and Society, 10(2), 90-105.

Osler, A. \& Vincent, K. (2003) Girls and Exclusion. Rethinking the Agenda. London: RoutlegeFalmer. Pillow, W. (2004) Unfit Subjects. Educational Policy and the Teen Mother. New York: RoutledgeFalmer.

Rapley, T. (2004) Interviews. In C. Seale, G. Giampeitro, J. Gubrium and D. Silverman (eds) Qualitative Research Practice. London: SAGE.

Reinharz, S. (1992) Feminist Methods in Social Research. New York: Oxford University Press.

Social Exclusion Unit (SEU) (1999) Teenage Pregnancy. London: Social Exclusion Unit.

Teenage Pregnancy Unit (TPU) (2005) Teenage Pregnancy Strategy Evaluation: Final Report Synthesis. London: Teenage Pregnancy Unit.

Williamson, E., Goodenough, T., Kent, J. \& Ashcroft, R. (2005) Conducting research with children: the limits of confidentiality and child protection protocols. Children and Society, 19(5), 397-409.

Young, I. M. (1990) Justice and the Politics of Difference. Princeton, NJ: Princeton University Press. 